\title{
PRODUKSI SABUN MANDI TRANSPARAN BERBAHAN BAKU VCO MENGANDUNG KAROTENOID TOMAT
}

\author{
Lidya Irma Momuat ${ }^{\left.{ }^{*}\right)}$ dan Audy Denny Wuntu ${ }^{1)}$ \\ ${ }^{1)}$ Program Studi Kimia FMIPA UNSRAT, Manado \\ ${ }^{*}$ Corresponding author: Imomuat@gmail.com \\ e-mail:dennywuntu@yahoo.com
}

\begin{abstract}
ABSTRAK
Penelitian ini bertujuan untuk produksi sabun mandi transparan dengan memanfaatkan VCO mengandung karotenoid tomat (VCO+tmt), serta menentukan kombinasi gliserol, etanol dan sukrosa yang optimum untuk bereaksi dengan VCO+tmt menghasilkan sabun transparan yang karakteristiknya memenuhi Standar Nasional Indonesia (SNI) no. 06-35321994 bagi sabun mandi. Sabun mandi transparan dibuat menurut metode Cognis (2003), dengan memvariasikan konsentrasi gliserol, etanol dan sukrosa (formula A, B, dan C). Produk sabun transparan dikarakterisasi menurut metode SNI no. 06-35321994 bagi sabun mandi, serta diamati warna, transparansi, kekerasan dan stabilitas busanya. Hasil penelitian menunjukan bahwa $\mathrm{VCO}+\mathrm{tmt}$ dapat digunakan dalam pembuatan sabun mandi transparan, dengan bilangan penyabunan VCO+tmt sebesar 225,37. Karakteristik sabun transparan yang dihasilkan berwarna orange kekuningan, transparansi dan tekstur formula $\mathrm{C}$ lebih baik daripada $\mathrm{A}$ dan $\mathrm{B}$, serta stabilitas busa sabun formula A, B dan C berturut-turut $89,29 \%, 96,88 \%$, dan 93,10\%. Kadar air, jumlah asam lemak dan asam lemak bebas dari sabun formula A, B dan C belum memenuhi SNI, sedangkan untuk kadar alkali bebas dan minyak mineral telah memenuhi SNI. Penelitian ini menyimpulkan bahwa karakteristik sabun transparan berbahan baku VCO+tmt formula $\mathrm{C}$ lebih baik daripada formula A dan B, namun belum memenuhi SNI no. 06-35321994.
\end{abstract}

Kata kunci: etanol, gliserol, sabun transparan, sukrosa, tomat, VCO

\section{PRODUCTION OF TRANSPARENT BATH SOAP FROM VCO CONTAINING TOMATO CAROTENOID}

\begin{abstract}
This study was aimed to produce transparent bath soap by utilizing VCO containing tomato carotenoids (VCO+tmt), and to determine the optimum combination of glycerol, ethanol and sucrose reacted with $\mathrm{VCO}+\mathrm{tmt}$ to produce transparent soap which meet requirements by Indonesian National Standard (SNI) no. 06-35321994 for bath soap. Transparent bath soaps were prepared according to Cognis (2003) method, by varying the concentrations of glycerol, ethanol and sucrose (formulas $\mathrm{A}, \mathrm{B}$, and $\mathrm{C}$ ). Transparent soap products were characterized according to SNI method no. 06-35321994 for bath soap, and were observed for the color, transparency, hardness and stability of the foam. The results showed that VCO+tmt could be used in making transparent bath soap, with saponizing number VCO tmt equal to 225,37. Soap produced had orange color, transparent, the texture of $\mathrm{C}$ was better than $\mathrm{A}$ and $\mathrm{B}$, and the stability of soap formulas A, B and C were $89.29 \%, 96.88 \%$, and $93.10 \%$, respectively. Water content, the amount of fatty acids and free fatty acids from soap of formula A, B and C did not meet SNI requirements, but free alkali and mineral oil met the requirements. It was concluded that the characteristics of transparent soap made from raw $\mathrm{VCO}+\mathrm{tmt}$ formula $\mathrm{C}$ was better than formula $\mathrm{A}$ and B, but did not meet conditions required by SNI no. 06-35321994.
\end{abstract}

Keywords: ethanol, glycerol, transparent soap, sucrose, tomato, VCO 


\section{PENDAHULUAN}

Tanaman Kelapa (Cocos nucifera) tersebar luas di Indonesia. Departemen Pertanian melaporkan bahwa pertanaman kelapa di Indonesia merupakan yang terluas di dunia dengan pangsa $31,2 \%$ dari total luas areal kelapa dunia. Tahun 2011 luas area perkebunan kelapa Indonesia sebesar 3.752.000 Ha dengan jumlah produksi 3.204.050 ton (Direktorat Jendral Perkebunan Kementerian Pertanian, 2012). Namun, baik jumlah maupun ragam produk ekspor kelapa Indonesia masih di bawah Filipina.

Bagi sebagian masyarakat Indonesia, termasuk di daerah Sulawesi Utara, kelapa merupakan bagian dari kehidupannya karena dapat dimanfaatkan untuk memenuhi kebutuhan ekonomi, sosial dan budaya. Pentingnya kelapa bagi masyarakat juga tercermin dari luasnya areal perkebunan rakyat yang mencapai $98 \%$ dari 3,74 juta ha dan melibatkan lebih dari tiga juta rumah tangga petani.

Kopra sebagai produk primer kelapa yang banyak diusahakan oleh masyarakat secara tradisional, saat ini daya saing ekspornya mulai menurun. Harga kopra sangat fluktuatif, dan cenderung menurun sampai biaya produksinya lebih tinggi daripada nilai ekspornya, sehingga tidak banyak memberikan keuntungan bagi petani. Untuk meningkatkan pendapatan petani, perlu diupayakan inovasi teknologi pengolahan yang tepat bagi setiap bagian kelapa, serta diversifikasi hasil olahan kelapa sehingga dapat menghasilkan beragam produk yang berkualitas dan bernilai jual tinggi. Industri kelapa yang berkembang baik saat ini adalah pengolahan minyak kelapa menjadi senyawa oleokimia dan turunannya, seperti sabun mandi.

Beragam produk minyak kelapa telah dihasilkan, di antaranya virgin coconut oil mengandung karotenoid tomat (VCO+tmt) (Momuat et al., 2009). Senyawa karotenoid merupakan senyawa antioksidan yang dapat berfungsi sebagai scavenger radikal bebas dalam tubuh dan kulit (Skibsted, 2012; Darvin et al., 2011). Karenanya, VCO+tmt dapat dimanfaatkan baik dalam industri pangan (misal: minyak makan) maupun non-pangan (misal, kosmetik). Pada penelitian ini, VCO+tmt akan digunakan sebagai bahan baku untuk membuat produk kosmetik, yakni sabun mandi transparan.

Sabun mandi transparan pada dasarnya sama dengan sabun mandi opaque, yakni dihasilkan dari reaksi antara minyak dan $\mathrm{NaOH}$; berbentuk padat, berbusa, digunakan sebagai pembersih, dengan penambahan zat pewangi, dan bahan lainnya yang tidak membahayakan kesehatan (Badan Standarisasi Nasional, 1994). Untuk meningkatkan transparansi sabun digunakan bahan tambahan berupa gliserol, alkohol alifatik $\left(\mathrm{C}_{1}-\mathrm{C}_{2}\right)$ dan gula (sukrosa) (White \& Morrow, 2002). Keunggulan sabun transparan dibanding sabun opague terletak pada penampakannya yang transparan, berwarna jernih dan permukaan yang mengkilap, menghasilkan busa lebih lembut di kulit, serta harganya relatif lebih mahal. Karakteristik sabun transparan yang dihasilkan tergantung pada jenis dan komposisi bahan baku yang digunakan.

Sejauh ini belum diperoleh informasi mengenai pemanfaatan $\mathrm{VCO}+\mathrm{tmt}$ dalam pembuatan sabun transparan, teristimewa informasi mengenai konsentrasi optimum dari gliserol, etanol dan sukrosa yang direaksikan dengan $\mathrm{VCO}+\mathrm{tmt}$ untuk menghasilkan sabun transparan yang memenuhi Standar Nasional Indonesia (SNI) no. 06-35321994 bagi sabun mandi.

Tujuan khusus penelitian ini adalah: (1) menentukan kombinasi konsentrasi gliserol, etanol, dan sukrosa yang optimum untuk bereaksi dengan VCO+tmt menghasilkan sabun mandi transparan; (2) menentukan karakteristik sabun mandi transparan yang dihasilkan menurut metode SNI; serta (3) mengetahui penerimaan konsumen terhadap produk sabun mandi transparan yang dihasilkan melalui uji organoleptik dan analisis finansialnya.

Urgensi penelitian ini adalah memberikan informasi ilmiah mengenai kombinasi konsentrasi VCO+tmt, gliserol, etanol dan sukrosa yang optimum untuk menghasilkan sabun mandi transparan yang memenuhi kualitas SNI. Aplikasi VCO mengandung karotenoid tomat pada formulasi sabun transparan diharapkan dapat bermanfaat dalam menambah nilai ekonomis bagi VCO tersebut, serta nantinya dapat berkontribusi dalam pengembangan agribisnis kelapa yang berperan penting 
untuk peningkatan produktivitas dan sekaligus peningkatkan pendapatan petani kelapa di Indonesia.

\section{METODE PENELITIAN}

\section{Alat dan Bahan}

Alat yang akan digunakan dalam penelitian ini adalah baskom stainles steel, pipet mohr, pipet tetes, cawan porselin, Erlenmeyer $250 \mathrm{~mL}$, labu takar $500 \mathrm{~mL}$, statif, klem, buret $50 \mathrm{~mL}$, termometer, corong pisah, hot plate, alat penghitung koloni, lemari pengeram, sentrifuge, pendingin tegak, neraca analitik, oven, desikator, pemanas, neraca kasar, blender, parutan kelapa, wadah plastik, ember, kain saring, kertas lakmus, cetakan sabun dan batang pengaduk.

Bahan yang akan digunakan adalah buah kelapa dalam berumur sekitar 12 bulan, tomat apel, akuades, asam stearat, $\mathrm{NaOH}$, gliserol, etanol, sukrosa, dietanolamida (DEA), $\mathrm{NaCl}$, asam sitrat, akuades, metil jingga, $\mathrm{H}_{2} \mathrm{SO}_{4}$, mikro parafin, fenolftalein, $\mathrm{KOH}, \mathrm{HCl}$, dan metil merah.

\section{Prosedur Penelitian}

Penelitian ini diawali dengan pembuatan VCO+tmt menurut metode Momuat et al. (2009). Minyak yang dihasilkan (VCO+tmt) selanjutnya ditentukan bilangan penyabunannya menurut Ketaren (2012), dan digunakan sebagai bahan baku untuk pembuatan sabun transparan.

\section{Pembuatan sabun mandi transparan}

Pembuatan sabun mandi transparan menggunakan formulasi dasar menurut Cognis (2002). Pada penelitian ini, sabun mandi transparan dibuat dari $\mathrm{VCO}+\mathrm{tmt}$ sebagai bahan baku utama, dengan memvariasikan konsentrasi gliserol, etanol, dan sukrosa. Variasi konsentrasi dilakukan pada transparent agent untuk mendapatkan sabun berbahan baku utama VCO+tmt yang berkualitas SNI.

Proses pembuatan sabun transparan diawali dengan mecairkan asam stearat pada suhu $70^{\circ} \mathrm{C}$, lalu dicampur dengan $\mathrm{VCO}+\mathrm{tmt}$ sesuai formulasi yang telah ditentukan (A, B dan C). Campuran direaksikan dengan $\mathrm{NaOH} 30 \%$ sambil terus diaduk pada suhu $70{ }^{\circ} \mathrm{C}$ hingga homogen, dan terbentuk stok sabun yang keras. Selanjuntnya, stok sabun ditambahkan etanol, gliserol, sukrosa, asam sitrat, DEA, $\mathrm{NaCl}$ dan air secara berurutan sambil terus diaduk. Larutan sabun yang telah homogen dituangkan dalam cetakan dan didiamkan selama 24 jam pada suhu ruang, untuk kemudian dikarakterisasi kualitasnya menurut metode SNI no.063532-1994 (Badan Stadarisasi Nasional, 1994), serta warna, transparansi, tekstur (kekerasan) dan stabilitas busa sabun (Goon et al., 1999).

\section{HASIL DAN PEMBAHASAN}

\section{Produk VCO Mengandung Karotenoid Tomat (VCO+tmt)}

VCO mengadung karotenoid tomat (VCO+tmt) dibuat dari daging buah kelapa dalam yang sudah tua (penampakkan fisik tempurung kelapa berwarna coklat tua) dan buah tomat yang telah masak. Kelapa yang digunakan sebanyak 23 butir, dengan total daging kelapa parut seberat $11.925 \mathrm{~g}$ atau rata-rata $518 \mathrm{~g}$ daging buah kelapa dalam setiap butir kelapa. Setelah santan diperoleh dan didiamkan selama 2 jam, dihasilkan krim santan sebanyak $6.840 \mathrm{~mL}$. Krim santan ditambahkan dengan sari tomat sebanyak $2.931 \mathrm{~mL} \quad(30 \%)$, atau perbandingan krim santan dan sari tomat 7:3. Penelitian Momuat et al. (2009) melaporkan bahwa rendemen $\mathrm{VCO}+\mathrm{tmt}$ tertinggi $(35,71 \%)$ dihasilkan pada konsentrasi sari tomat $30 \%$ dalam krim santan.

VCO+tmt yang dihasilkan pada penelitian ini sebanyak $2.395 \mathrm{~mL}$ atau $35,02 \%$ dari krim santan yang digunakan. VCO+tmt yang dihasilkan berwarna merah kekuning-kuningan. Canene-Adams et al. (2005) melaporkan bahwa tomat mengandung senyawa antioksidan seperti likopen yang dapat menghambat atau mencegah terjadinya reaksi oksidasi. Likopen termasuk dalam kelompok karotenoid yang mempunyai aktivitas antioksidan yang cukup tinggi serta memberikan pigmen warna merah pada tomat. Likopen merupakan senyawa yang bersifat non-polar dan dapat larut dalam minyak. Pada penelitian ini, warna merah kekuning-kuningan pada $\mathrm{VCO}+\mathrm{tmt}$ disebabkan oleh senyawa likopen yang larut ke dalam minyak. 


\section{Bilangan Penyabunan VCO+tmt}

Bilangan penyabunan adalah jumlah miligram $\mathrm{KOH}$ yang diperlukan untuk menyabunkan 1 gram minyak atau lemak (Ketaren, 2012). Bilangan penyabunan biasanya berhubungan dengan berat molekul suatu lemak/minyak. Jika suatu minyak memiliki berat molekul lebih kecil, maka bilangan penyabunannya lebih besar daripada minyak dengan berat molekul lebih besar. Bilangan penyabunan pada penelitian ini ditentukan untuk mengetahui jumlah $\mathrm{KOH}$ yang dibutuhkan untuk direaksikan dengan $50 \mathrm{~g}$ VCO+tmt sehingga tepat bereaksi. Besarnya bilangan penyabunan untuk VCO+tmt adalah 225,37. Artinya untuk menyabunkan $1 \mathrm{~g}$ VCO+tmt dibutuhkan 225,37 $\mathrm{mg} \mathrm{KOH}$. Berdasarkan bilangan penyabunan ini, diperoleh jumlah $\mathrm{KOH}$ sebesar 11,45 g untuk menyabunkan $50 \mathrm{~g}$ minyak.

Bilangan penyabunan VCO menurut standar Asian and Pacific Coconut Community (APCC) (2005), yakni 250-260. Pada penelitian ini, bilangan penyabunan VCO+tmt sebesar 225,37 tidak memenuhi standar APCC, karena VCO+tmt mengandung komponen asam lemak campuran dari kelapa dan tomat. Bilangan penyabunan minyak biji tomat sebesar 193 (Kamazani et al., 2014), sehingga menurunkan bilangan penyabunan dari VCO+tmt.

\section{Karakteristik Produk Sabun Mandi Transparan}

Karakteristik sabun transparan berbahan baku $\mathrm{VCO}+\mathrm{tmt}$ yang dibuat dengan variasi konsentrasi gliserol, etanol dan sukrosa (formula A, B dan C) tertera pada Tabel 1. Sabun mandi transparan yang dihasilkan berwarna kuning dengan intensitas yang sama, bila diamati secara visual. Warna tersebut disebabkan oleh warna VCO+tmt yang digunakan, yang mengandung karotenoid sebagai pigmen dalam buah tomat.

Sabun formula C memiliki transparansi yang lebih tinggi daripada sabun formula A dan B. Sabun formula C dibuat dengan konsentrasi gliserol dan sukrosa yang lebih tinggi dan kadar etanol yang lebih rendah daripada sabun formula $\mathrm{A}$ dan B. Menurut Hambali et al. (2005), etanol berlebih tidak dapat meningkatkan transparansi. Transparansi yang relatif tinggi pada sabun formula $\mathrm{C}$, dapat disebabkan oleh kadar etanol yang relatif rendah serta kadar gliserol dan sukrosa yang relatif tinggi.

Tabel 1. Karakteristik Sabun Transparan

\begin{tabular}{lccc}
\hline \multicolumn{1}{c}{ Deskripsi } & \multicolumn{4}{c}{ Formula Sabun Transparan } \\
\multicolumn{1}{c}{ Produk } & A & B & C \\
\hline Warna orange & ++ & ++ & ++ \\
kekuningan & & & \\
Transparansi & + & ++ & +++ \\
Tekstur & + & ++ & +++ \\
(kekerasan) & & & \\
Stabilitas busa & $89,29 \%$ & $96,88 \%$ & $93,10 \%$ \\
\hline
\end{tabular}

Keterangan: $+=$ cukup, $++=$ sedang, $+++=$ baik

Sabun formula $\mathrm{C}$ memiliki tekstur yang lebih keras daripada sabun formula A dan B (Tabel 1). Tekstur yang relatif lebih keras pada sabun mandi transparan formula C disebabkan oleh kadar sukrosa yang relatif lebih tinggi dan kadar air yang relative rendah daripada formula A dan B. Sukrosa berfungsi mencegah kristalisasi dan meningkatkan kekerasan produk sabun transparan (Hambali et al., 2005).

Stabilitas busa ke-3 formulasi sabun mandi transparan berada di atas nilai $89 \%$ (Tabel 1). Sabun mandi transparan formula B memiliki stabilitas busa tertinggi, diikuti formula $\mathrm{C}$ dan $\mathrm{A}$.

\section{Kadar Air}

Pada penelitian ini, kadar air sabun transparan tertinggi diperoleh pada formula A, diikuti formula B dan C (Tabel 2). Perbedaan kadar air dalam ke-3 sabun transparan tersebut disebabkan oleh perbedaan jumlah air yang ditambahan saat produksi sabun. Air yang ditambahkan dalam formulasi sabun transparan A, B dan C berturut-turut sebanyak 7,8\%, 4,8\% dan $1,8 \%$. Semakin banyak jumlah air yang ditambahkan, semakin besar kandungan air dalam produk sabun transparan. Kadar air dalam sabun transparan yang dihasilkan berkisar antara $18,74 \%$ sampai $27,30 \%$, yang berarti belum memenuhi kriteria mutu sabun mandi menurut SNI, yaitu maksimal $15 \%$ untuk kadar air.

Kadar air dalam sabun akan mempengaruhi tekstur sabun dan kelarutan sabun dalam air pada saat digunakan. Sabun 
dengan kadar air yang tinggi mempunyai tekstur yang lebih lunak daripada sabun dengan kadar air rendah.

\section{Jumlah Asam Lemak}

Jumlah asam lemak adalah jumlah seluruh asam lemak dalam sabun transparan, baik asam lemak yang tidak maupun yang telah bereaksi dengan alkali $(\mathrm{NaOH})$ membentuk sabun. Jumlah asam lemak dalam sabun transparan pada penelitian ini berkisar antara 29\%-31\% (Tabel 2). Sabun transparan formula A memiliki jumlah asam lemak tertinggi $(31,61 \%)$, diikuti formula $\mathrm{C}$ dan B. Jumlah asam lemak pada ke-3 produk sabun transparan belum memenuhi kriteria mutu sabun mandi menurut SNI, yaitu lebih dari $70 \%$ untuk jumlah asam lemak. Pada formulasi pembuatan sabun mandi transparan, asam lemak yang ditambahkan hanya sebesar $28 \%$, yang bersumber dari $8 \%$ asam stearat dan $20 \%$ VCO mengandung karotenoid tomat. Hal inilah yang menyebabkan ke-3 sabun transparan sulit untuk memenuhi SNI No. 06-3532-1994.

Sabun yang baik memiliki jumlah asam lemak lebih besar dari $70 \%$, artinya bahan utama dalam pembuatan sabun (reaksi saponifikasi) adalah minyak atau lemak (70\%), sedangkan bahan-bahan tambahan lainnya kurang dari $30 \%$. Asam lemak bila bereaksi dengan senyawa alkali $(\mathrm{NaOH})$ akan membentuk garam asam lemak (sabun) yang berfungsi sebagai surfaktan, sehingga kotoran berupa minyak atau lemak dapat dibersihkan saat sabun digunakan.

Tabel 2. Kualitas Sabun berdasarkan uji SNI No. 06-3532-1994

\begin{tabular}{llcccc}
\hline No. & Uraian & SNI & A & B & C \\
\hline 1. & Kadar air, \% & Maks. 15 & 27,30 & 22,93 & 18,74 \\
2. & Jumlah Asam lemak, \% & $>70$ & 31,61 & 29,13 & 30,70 \\
3. & Alkali Bebas & Maks. & 0 & 0 & 0 \\
& -dihitung sebagai NaOH, \% & 0,1 & & & \\
4. & Asam lemak bebas dan & 2,5 & 5,00 & 5,19 & 3,99 \\
& Atau lemak netral, $\%$ & Negatif & Negatif & Negatif & Negatif
\end{tabular}

Keterangan: A, B dan C = formula sabun transparan

\section{Kandungan Alkali Bebas}

Alkali bebas adalah alkali dalam sabun yang tidak terikat sebagai senyawa. Pada proses pembuatan sabun, alkali $(\mathrm{NaOH})$ akan bereaksi dengan minyak atau lemak membentuk sabun. Penggunaan alkali melebihi stoikiometri reaksinya menyebabkan ada sejumlah alkali yang tidak ikut bereaksi, dan berada dalam keadaan bebas. Kelebihan alkali dalam produk sabun dapat menyebabkan iritasi pada kulit. Kelebihan alkali pada sabun mandi dapat disebabkan oleh besarnya konsentrasi alkali yang ditambahkan pada proses penyabunan, sehingga meningkatkan $\mathrm{pH}$ sabun.

Pada penelitian ini, ke-3 produk sabun transparan tidak mengandung alkali bebas (0\%) (Tabel 2). Sabun transparan yang tidak mengandung alkali bebas menunjukkan bahwa jumlah $\mathrm{NaOH}$ yang ditambahkan telah habis bereaksi dengan minyak membentuk sabun. Kandungan alkali bebas pada ke-3 produk sabun transparan telah memenuhi kriteria mutu sabun mandi menurut SNI 06-3532-1994, yaitu maksimum 0,1 untuk alkali bebas dihitung sebagai $\mathrm{NaOH}$.

\section{Kandungan Asam Lemak Bebas}

Asam lemak bebas adalah asam lemak yang berada dalam sabun, tetapi tidak terikat sebagai senyawa natrium ataupun senyawa trigliserida. Pada penelitian ini, kandungan asam lemak bebas terendah terdapat dalam sabun mandi transparan $\mathrm{C}$ $(3,99 \%)$, diikuti A (5\%) dan B (5,19\%) (Tabel 2). Kandungan asam bebas pada ke-3 produk sabun transparan belum memenuhi kriteria mutu sabun mandi menurut SNI 063532-1994, yaitu kurang dari 2,5\% untuk asam lemak bebas. Tingginya asam lemak bebas dalam ke-3 produk sabun mandi transparan menunjukkan bahwa masih banyak minyak yang belum bereaksi dengan $\mathrm{NaOH}$, yang disebabkan oleh kurangnya konsentrasi $\mathrm{NaOH}$ yang digunakan. 


\section{Lemak yang Tidak Tersabunkan}

Brown et al. (2015) melaporkan bahwa pada proses pembuatan sabun terdapat komponen-komponen lemak dan minyak yang tidak dapat tersabunkan oleh perlakuan kaustik biasa. Komponen yang tidak tersabunkan tersebut di antaranya adalah senyawa alkohol alifatik, sterol, pigmen, minyak mineral dan hidrokarbon, serta umumnya non-volatil pada $103{ }^{\circ} \mathrm{C}$.

Lemak yang tidak tersabunkan dari ke-3 formulasi sabun transparan pada penelitian ini sebesar $0.01 \%$. Komponen lemak yang tidak tersabunkan dapat berupa senyawa trigliserida dan karotenoid tomat yang terkandung dalam VCO+tmt. Senyawa karotenoid, seperti likopen, merupakan pigmen yang terdapat pada tomat, yang larut dalam VCO+tmt.

\section{Minyak Mineral}

Minyak mineral adalah minyak yang berasal dari penguraian bahan organik oleh jasad renik seperti minyak bumi dan turunannya. Minyak mineral tidak dapat disabunkan, walaupun degan $\mathrm{NaOH}$ berlebih. Minyak mineral dalam sabun bila ditambahkan air akan membentuk emulsi air dan minyak yang ditandai adanya kekeruhan.

Hasil pengujian terhadap ke-3 sabun transparan pada penelitian ini menunjukkan tidak adanya minyak mineral. Kandungan minyak mineral pada ke-3 produk sabun transparan telah memenuhi kriteria mutu sabun mandi menurut SNI 06-3532-1994, yaitu negatif untuk minyak mineral.

\section{KESIMPULAN}

Penelitian ini menyimpulkan bahwa VCO yang mengandung karotenoid tomat (VCO+tmt) dapat digunakan dalam pembuatan sabun mandi transparan. Besarnya bilangan penyabunan untuk VCO+tmt adalah 225,37. Karakteristik ke-3 sabun transparan yang dibuat dari VCO+tmt, dengan variasi konsentrasi gliserol, etanol dan sukrosa berwarna orange kekuningan, transparansi dan tekstur formula $\mathrm{C}$ lebih baik daripada A dan B, serta stabilitas busa ke-3 formulasi sabun di atas 89,29\%. Kadar air, jumlah asam lemak dan asam lemak bebas dari ke-3 formulasi sabun transparan belum memenuhi SNI No. 06-3532-1994, sedangkan untuk parameter alkali bebas dan minyak mineral telah memenuhi SNI. Karakteristik sabun transparan berbahan baku VCO+tmt formula $\mathrm{C}$ lebih baik daripada formula $\mathrm{A}$ dan $\mathrm{B}$, namun belum memenuhi SNI no. 06-35321994.

\section{DAFTAR PUSTAKA}

Asian and Pacific Coconut Community. 2005. Coconut Statistical Yearbook: Standard For Virgin Coconut Oil. http://www.apccsec.org/document/V CNO.pdf [23 Desember 2010]

Badan Standarisasi Nasional. 1994. Standar Nasional Indonesia (SNI). Sabun mandi padat. SNI.

Brown, H. J., L.R. Copeland, R. Kleiman, S. Koritala, M.K. Cummings. 2015. High Unsaponifiables and Methods of Using The Same. United States Patent. Patent No. : US 8,927,034 B2

Cognis. 2002. Clear Bar Soap, Formulation No: GWH 96/25. Care Chemical Division PT. Cognis Indonesia, Jakarta.

Darvin, ME, W. Sterry, J. Lademann and T. Vergou. 2011. The Role of Carotenoids in Human Skin. Molecules 16(12):10491-10506

Direktorat Jendral Perkebunan Kementerian Pertanian. 2012. Percepatan Pelaksanaan dan Penguatan Manajemen Program Pembangunan Perkebunan 2012. Disampaikan pada RAKERNAS Pembangunan Pertanian di Jakarta [http://www.deptan. go.id/Rakernas2012/11-Januari2012/

06-percepatan-pelaksanaanPerkebunan-program-kementan.pdf]

Hambali, E., T.K. Bunasor, A. Suryani dan G. A. Kusumah. 2005. Aplikasi dietanolamida dari asam laurat pada pembuatan sabun transparan. J. Tek. Ind. Pert. 15(2):46-53

Kamazani, NH, H. Tavakolipour, M. Hasani, M. Amiri. 2014. Evaluation and analysis of the ultrasound-assisted extracted tomato seed oil. Journal of Food Biosciences and Technology 4(2):57-66. 
Ketaren, S. 2012. Pengantar Teknologi Minyak dan Lemak Pangan. Penerbit Universitas Indonesia, Jakarta. Hal. 49-50.

Momuat, L.I., A. Wuntu, D. Hatidja, M. Runtu, V. Lengkong. 2009. Kualitas Minyak Kelapa dengan Penambahan Ekstrak Tomat pada Beberapa Waktu Penyimpanan dan Suhu Pemanasan. Jurnal Ilmiah Sains 9(1):149-156

Goon, P., R. G. Bhirud, V. V. Kumar. 1999. Detergency and foam studies on linear alkylbenzene sulfonate and secondary alkyl sulfonate. Journal of Surfactants and Detergents 2(4): 489-493

Skibsted, L.H. 2012. Carotenoids in Antioxidant Networks. Colorants or Radical Scavengers J. Agric. Food Chem. 60 (10): 2409-2417

White, J.M. and Morrow. 2002. Process for Enhancing the Transparency of Transparent Soap. United States Patent. US 6,479,441 B1. 